\title{
Simultaneous modeling of developer behavior and land prices in UrbanSim
}

\author{
Daniel Felsenstein \\ Eyal Ashbel \\ Hebrew University of Jerusalem ${ }^{a} \quad$ Hebrew University of Jerusalem ${ }^{\text {b }}$
}

\begin{abstract}
A strong inter-dependence exists between the decision to develop land and the expected returns to be gained from that development. Current practice in UrbanSim modeling treats developer behavior and the emergence of land prices as independent processes. This assumes that land prices are exogenous to the interaction between buyers and sellers - an assumption that is difficult to sustain in urban economics and real estate research. This paper presents an attempt to model the two processes as occurring simultaneously. Using the UrbanSim model for metropolitan Tel Aviv, we compare the results of forecasts for densities (residential and non-residential) and land values for the period 2001-2020. Our results show that simultaneous estimation tends to produce more accentuated outcomes and volatile trends. The validity of these results and the implications of this approach in the wider context of land use modeling are discussed.
\end{abstract}

Keywords: Land price, developer behavior, simultaneous equations, UrbanSim, endogeneity

\section{Introduction}

Much urban economics research points to the endogeneity in the relationship between developer behavior and land prices; developer behavior depends on land prices and land prices depend on developer behavior. In UrbanSim, while this independence is noted, the modeling strategy assumes prices are exogenous to interaction between buyers and sellers as their individual transactions are too small to affect aggregate prices. Similarly, jobs and households are assumed to be price-takers who don't have enough power to influence market prices. In practice, however, it is reasonable to assume that land prices and developer behavior are co-determined and occur simultaneously.

Dealing with this endogeneity also means addressing wider issues such as the correct identification of models (error structures), instrumentation, and dynamics. The treatment of dynamics is closely linked with the endogeneity of prices. In the current UrbanSim land price model, dynamics are dealt with through cross-sectional simulation of end-of-the-year-prices based on updated cell characteristics (from the developer model, household and jobs location choices, and the transport model). These land prices then influence households, jobs, and developer behavior in the following year. This "back-door" endogeneity is the result of these quasi-dynamics.

\footnotetext{
amsdfels@mscc.huji.ac.il
}

beyal.ashbel@gmail.com 
In this paper, we estimate the simultaneity between house prices and developer behavior. The paper reviews the way in which this interdependence and price endogeneity are dealt with in large-scale urban models. The paper also presents current practice in UrbanSim. After that, we present a simple model that highlights the complimentarity between land conversion and land price. We then outline an estimation strategy based on the work of Maddala (1983) that deals with a "mixed" system in which one variable is continuous and the other dichotomous. In the standard case of two continuous dependent variables, simultaneity is estimated by transferring the fitted values from one model into the other. However, in our case, as one variable is dichotomous, the variance matrix needs to be adjusted. After describing the UrbanSim model for metropolitan Tel Aviv, the paper proceeds to compare empirical results of two UrbanSim runs using this model. The first is based on the conventional UrbanSim practice of treating land price and developer behavior models independently. The second is based on a situation in which the two are co-determined. Our results point to greater volatility in results when simultaneous estimation is used-although this seems to settle down over the longer term. We discuss the validity of these results, compare them to actual data for recent years, and attempt to identify consistencies in the differences between the two methods.

\section{Literature Review}

Large-scale urban models originating from both the land use-transportation tradition and the micro-simulation world have made rapid advances in recent years. Many of these systems are comprehensively reviewed in Chang (2006), Hunt et al. (2005b), and Iacono et al. (2008). In this section, we first review the way in which existing models treat the two issues that form the focus of this paper-namely, the simultaneity that exists between developer behavior and land prices, and the exogeneity inherent in land prices. We then examine current practice in UrbanSim modeling with respect to these two topics.

The 'spatial interaction' framework provides the first class of models that address interdependencies between actors and markets. The ITLUP model, through its DRAM submodel (Putnam 1996), is probably the most popular of this class of analytic approaches, grounded in a Lowry-type allocation process. For our purposes, however, this class of models is something of a straw man. Households and workers are the only actors explicitly considered and only in respect to their demand for land (which is then allocated across zones). There is no direct consideration of the supply side, which is exogenously fixed by development and regulatory constraints. As such, no price structure emerges and no market clearing mechanism is specified.

A more challenging approach from our perspective is the class of 'bid-rent' transportation allocation models. These models, best exemplified by Martinez's MUSSA model (Martinez 1992, 1996, 2000), offer sophisticated market-clearing mechanisms for land markets and explicitly model developer behavior. The bid-rent mechanism is a central feature of this analytic system and draws on classic work by Rosen (1974) and Ellickson (1981) that coupled hedonic analysis within the bid-rent model. In this model, the market price for the bundle of attributes that comprise a location is jointly determined by the offer price of suppliers of services and the evaluation of those services by consumers. In the ensuing bidding process, offers are determined by willingness to pay and the model produces a pattern of land uses and values in which the users and the value of locations are mutually determined. 
In Martinez's 1992 "bid-choice" formulation of the Rosen-Ellickson bid rent model, developer behavior is explicitly addressed and land prices are treated as exogenous. The MUSSA model provides a static equilibrium for a given target year by adjusting developer behavior on the supply side and consumer utility levels on the demand side, in order to get supply and demand to balance. In contrast to the UrbanSim approach, this equilibrium is imposed. In line with UrbanSim, this model draws on strong micro-economic foundations in order to derive a demand-supply equilibrium and endogenous land prices. Similarly, as in UrbanSim, land prices at each time period depend only on the competitive bidding process inducing a delay effect as land supply changes in response to lagged land prices.

The third class of models we consider are "spatial economic" (or "input-output") models. A key feature of these models is the use of an explicit economic accounting approach that traces inter-sectoral spatial and monetary flows of goods and services between producers and consumers (input-output analysis). The monetary flows between sectors are used to derive the interdependencies between location and accessibility in the land use-transportation context. When money flows in one direction from buyer to seller, an opposite flow (of services, labor or land) usually occurs from seller to buyer. In land use-transportation modeling, this framework is applied to the world of developers who improve land and construct structures that are allocated according to endogenously generated demand. Various models such as TRANUS (de la Barra et al. 1984), MEPLAN (Hunt and Simmons 1993) and more recently PECAS (Hunt et al. 2005a) have been developed employing this approach.

The input-output basis of these models makes them uniquely able to incorporate spatial flows of goods and services. With respect to the issues that interest us, they are less unique. On the supply side, land is fixed at each time period. On the demand side, land consumption is elastic with respect to price. Land prices are endogenous and the short-run equilibrium is Walrasian rather than driven by competitive bidding (as in MUSSA) or random utility (as in UrbanSim). Developers allocate land to different zones as a function of the characteristics of the unit and its price. The short-run market equilibrium is reached within the time period.

Current practice in UrbanSim follows the models described above in some respects and diverges from them in others. In the core UrbanSim system, the models that simulate the behavior of the key agents in the urban arena are each estimated independently (household and employment location models, household and employment mobility models, developer model, land price model, etc.). These models do not drive each other. Rather, they interact through shared data that is pooled in the system's object store, allowing them to monitor changes in each others' data fields and to coordinate their activities. Once estimated, the model coefficients are re-incorporated into the UrbanSim system through a translation and aggregation layer that mediates between the object store and the models themselves. These coefficients drive the allocation process of the model and the placement of households and workers in vacant cells.

UrbanSim modeling practice is at odds with the urban economics literature in its representation of the relationship between developer behavior and land prices in two respects. First, developer behavior and land prices are not treated as interdependent. In practice, however, the choice to convert a parcel of land to a different use is jointly determined with the expected return from that parcel. Second, UrbanSim treats land prices as exogenous. The justification for this is that individual buyers and sellers in the land market are too small-scale to directly influence prices (Waddell and Ulfarsson 2003) although in aggregate this would presumably not hold. Similarly, households and workers who relocate are assumed to lack the market power to 
influence prices (Waddell et al. 2003). These are convenient assumptions that bypass the need to model how a price structure emerges and the market clears. They also mitigate the need to deal with the complexities of asymmetric information, expectations, and search processes in the land market.

This is not to say that the endogeneity inherent in simulation models of social choices (where to live, work, etc.) has been overlooked by the developers of UrbanSim. Waddell (2005) notes some of the drawbacks of the market-clearing mechanism in UrbanSim whereby prices respond at the end of the year to characteristics of locations and to the balance of supply (vacancy rates) and demand at each location. This makes the land price model essentially an 'end-ofthe-year' model in which quasi-dynamics come through changes in grid cell attributes (due to the developer model, household and job location models, and the transport model). The updated cell characteristics become the land prices that influence household job location choice and developer behavior in the next year. In order to replace this rather mechanistic process, the simulation of a 'landlord' agent that mediates between buyers and sellers in order to ensure balance between supply and demand has been suggested (Waddell 2005).

Recent work on capacity constraints in housing markets also notes that markets may not fully clear, thereby limiting the choices available to agents such as buyers and developers (de Palma 2007). This work notes two sources of bias that may arise in these constrained markets. The first results from the limited choice of alternatives available to agents. The second arises from the fact that land or house prices are co-determined with agent behavior in these markets and from the endogeneity inherent in this process that needs to be addressed.

The simultaneity between house prices and other features of the land market such as urban size (Goffette-Nagot 2008), regulatory practices (Ihlanfeldt 2007), and new construction (Mayer and Somerville 2000) has generated extensive attention in the urban economics and real estate literature. Within the UrbanSim modeling system, the issue has been partially addressed by end-of-the-year adjustments. We investigate whether these quasi-dynamics can be improved by the use of simultaneous estimation.

\section{A Simple Model}

To illustrate the simultaneity between land prices and developer behavior, we posit the following aggregate model (Figure 1) that incorporates relative pricing. The short run supply and demand balance at each time period is assumed to retain the hedonic structure in UrbanSim with the addition of price expectations. Land is supplied by the landowner/developer (we assume them to be synonymous) with supply curve $S$. We assume two types of land, $A$ and $B$. The relative price of land $\pi$ is $P_{A} / P_{B}$. The supply of land $\sigma$ in $A$ is $L_{A} / L$. The amount of land supplied is a positive function of relative price, expected relative price in the future $\pi^{e}$ and a factor $Z$ that includes all other influences (externalities, etc.). $Z$ also causes the supply curve to shift to the right, as shown in equation (1). If the error term $u$ is correlated with $\pi_{t}$, this will have a negative effect on $\sigma_{t}$.

$$
\sigma_{t}=F_{\sigma}\left(\pi_{t}, \pi_{t+1}^{e}, Z_{t}\right)+u
$$

Demand is posited as a negative function of relative price, as shown in (2). $X$ expresses all the factors that that push the demand curve to the right. If $\pi_{t}$ and $v$ are correlated, this will 
have a positive effect on demand. The market clears when $\sigma_{t}=d_{t}$.

$$
d_{i t}=F_{d}\left(\pi_{t}, X_{t}\right)+v
$$

In the disaggregated case, the observation is the $i$ th land parcel. The price of parcel $i$ in use $A$ at time $t$ is $P_{A i t}$ and, as before, $\pi_{i t}=P_{A i t} / P_{B i t}$. The amount of land to be converted is now:

$$
\sigma_{i t}=\alpha_{i}+\beta \pi_{i t}+\gamma \pi_{i t+1}^{e}+\lambda Z_{i t}+U_{i t}
$$

The demand for land is :

$$
d_{i t}=\theta \pi_{i t}+\mu X_{i t}+V_{i t}
$$

It should be noted that the relative price for parcel $i$ is in relation to the average price, i.e. $\theta\left(\pi_{i t}-\bar{\pi}_{t}\right)$, and that the aggregate price represents the sum of all land parcels, i.e. $\pi_{t}=$ $\sum_{i=1}^{n} w_{i} \pi_{i t}$.

Finally, we assume rational expectations. This means that the future land price is based on some expected price and an error term: $\pi_{i t+1}=\pi_{i t+1}^{e}+v_{i t+1}$. Again, the error term is of importance here. People do not expect to err and therefore expected future error $E\left(v_{i t+1}\right)=0$. Additionally, people analyze current information when formulating their expectations. Therefore the error is also influenced by $\Omega$, a current information factor for formulating future relative prices such that $E\left(v_{i t+1} \Omega_{i t}\right)=0$.

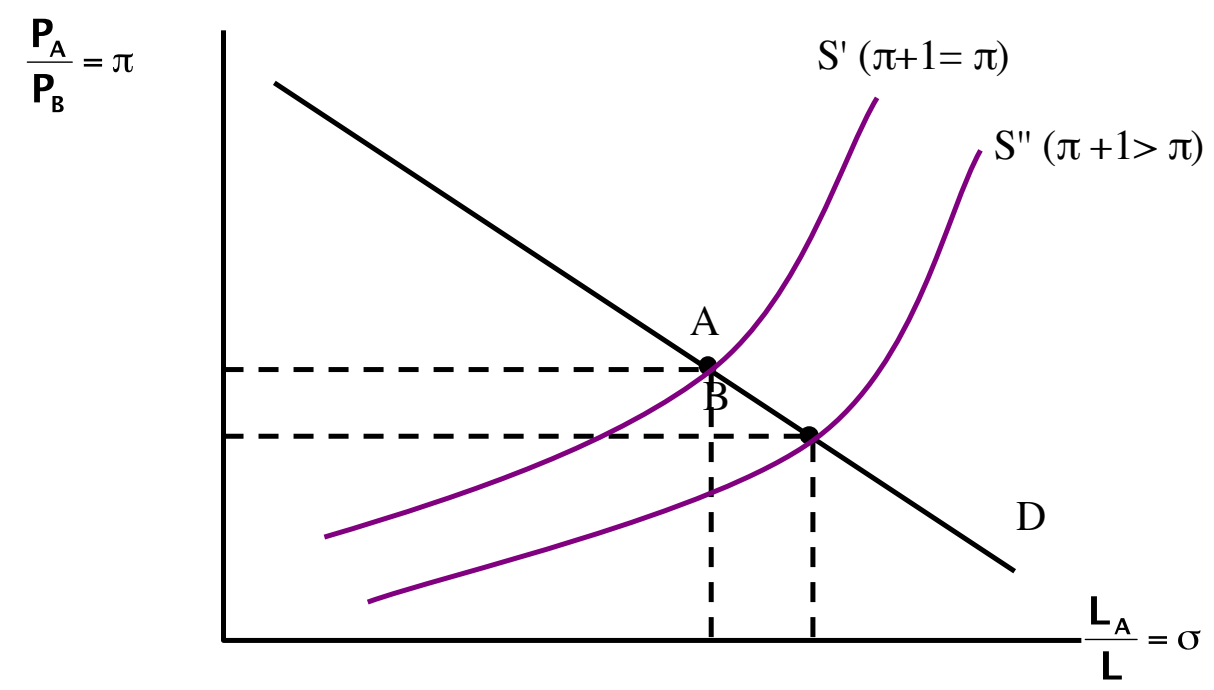

Figure 1: Supply and demand in the land market.

\section{Method and estimation technique}

Our estimation strategy is based on Maddala (1983) and incorporates the use of probit twostage least squares (P2SLS) to estimate simultaneous equations for land prices and developer behavior. We adopt an iterative process (described below) in order to attain partial equilibrium. 
Formulating a joint sub-system incorporating land prices and developer behavior presents various estimation challenges as the former is an observed continuous variable while the latter is dichotomous. As such, the standard 2SLS approach where both endogenous variables are continuous is clearly not suitable. The estimation strategy suggested by Maddala (1983) involves creating instruments for the endogenous variables in the first stage and substituting them into the structural equations in the second stage. To operationalize this, we use the CDSIMEQ twostage routine programmed in STATA (Keshk 2003). In Stage 1 (estimated by OLS and probit), models are fitted using all exogenous variables and the predicted values obtained. From these reduced-form estimates, predicted values from each model are obtained for use in Stage 2. In this stage, the original endogenous variables from the first stage are replaced by their fitted values. Finally, we correct for standard errors (adjustment of the variance-covariance matrices) as the models are based on predicted values and not on the appropriate observed values.

In our case the two-equation system consists of a land price model $\left(y_{1}\right.$, continuous variable) estimated by OLS and a developer model ( $y_{2}$, dichotomous variable) estimated by probit, as follows:

$$
\begin{aligned}
& y_{1}=\gamma_{1} y_{2}^{*}+\beta_{1} \mathbf{X}_{1}+u_{1} \\
& y_{2}^{*}=\gamma_{2} y_{1}+\beta_{2} \mathbf{X}_{2}+u_{2}
\end{aligned}
$$

Note that while $y_{1}=y_{1}^{*}, y_{2}^{*}$ is observed as a dichotomous endogenous variable, i.e. it is equal to 1 if $y_{2}^{*}>0$ and equal to 0 otherwise.

As $y_{2}^{*}$ is not observed (i.e., only observed as a dichotomous variable), the structural equations (5) and (6) are re-written dividing through by standard errors:

$$
\begin{aligned}
y_{1} & =\gamma_{1} \sigma_{2} y_{2}^{* *}+\beta_{1}^{\prime} \mathbf{X}_{1}+u_{1} \\
y_{2}^{* *} & =\frac{\gamma_{2}}{\sigma_{2}} y_{1}+\frac{\beta_{2}^{\prime}}{\sigma_{2}}+\mathbf{X}_{2} \frac{u_{2}}{\sigma_{2}}
\end{aligned}
$$

The two-stage estimation then proceeds with the estimation of reduced-form OLS and probit models for house prices and developer behavior respectively:

$$
\begin{aligned}
y_{1} & =\prod_{1} \mathbf{X}_{1}+v_{1} \\
y_{2}^{* *} & =\prod_{2} \mathbf{X}_{2}+v_{2}
\end{aligned}
$$

where $\mathbf{X}$ is the matrix of all exogenous variables and $\Pi_{1}, \Pi_{2}$ are vectors of parameters to be estimated.

The predicted values from equations (9) and (10), $\hat{y}_{1}, \hat{y}_{2}^{* *}$, are plugged back into the model for the second-stage estimation. Thus, the original endogenous variables in (5) and (6) are replaced by their fitted values from (9) and (10):

$$
\begin{aligned}
y_{1} & =\gamma_{1} \hat{y}_{2}^{* *}+\beta_{1} \mathbf{X}_{1}+u_{1} \\
y_{2}^{* *} & =\gamma_{2} \hat{y}_{1}+\beta_{2} \mathbf{X}_{2}+u_{2}
\end{aligned}
$$

Finally, a correction for the estimated standard errors is needed. These are based on $\hat{y}_{2}^{* *}, \hat{y}_{1}$ and not on $y_{2}^{* *}, y_{1}$. The CDSIQEM procedure adjusts the variance-covariance matrices and produces corrected variances for use in equations (7) and (8). 


\section{Data}

We illustrate the simultaneous estimation using an UrbanSim model calibrated for the Tel Aviv metropolitan region. This area represents the economic heartland of Israel and is the national gateway to the global economy (Kipnis 2009). The extent of economic agglomeration in Tel Aviv is underscored by the fact that the area produces 49 percent of national GNP, houses over 40 percent of the national population and provides 30 percent of all national employment while accounting for only seven percent of Israel's land area (Figure 2). Furthermore, the region is home to over 60 local authorities representing nearly a quarter of all city governments in Israel.

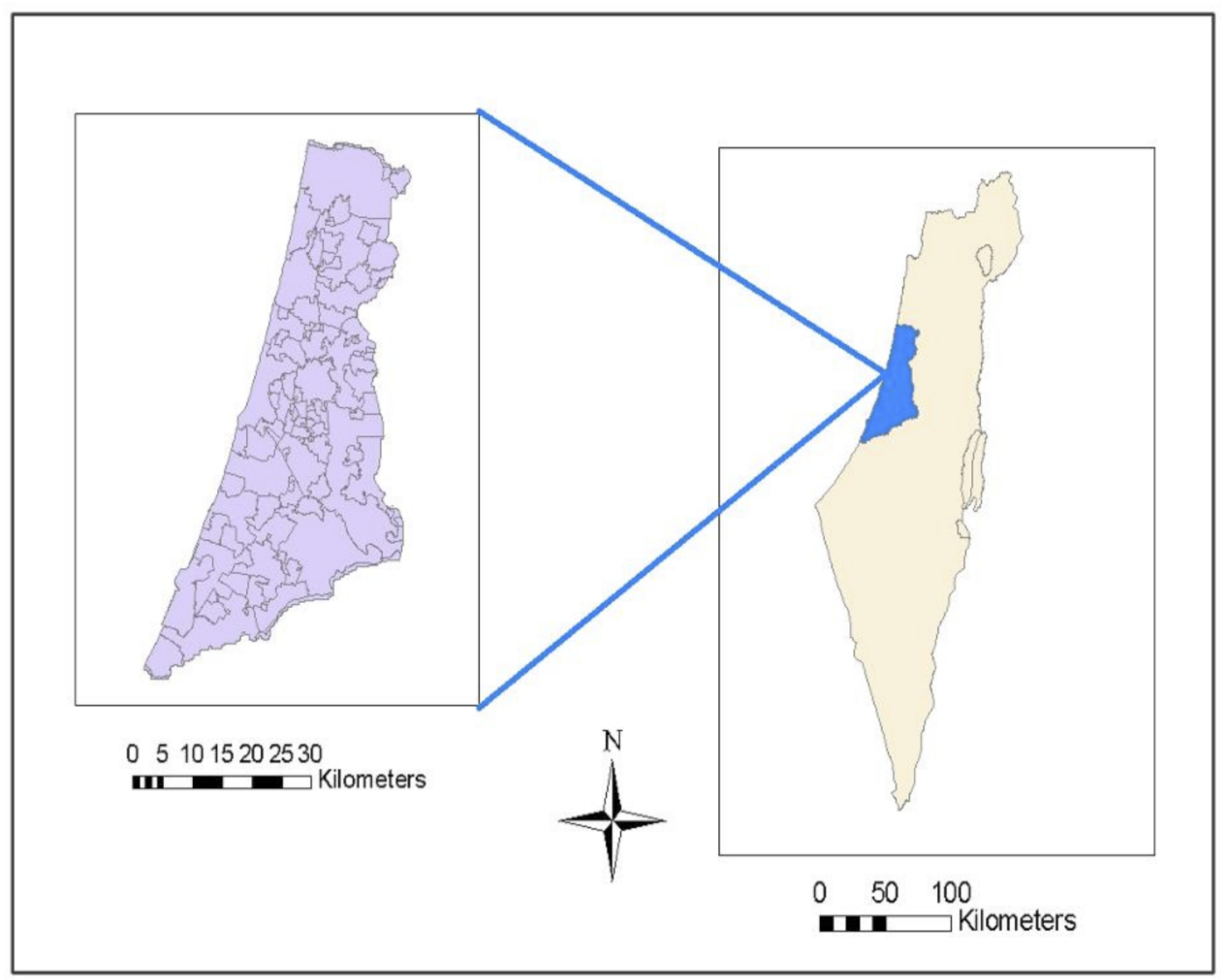

Figure 2: The Tel Aviv metropolitan area.

The preparation of the six key UrbanSim tables required data from a variety of sources. The contents of the households table were derived from the National Census 1995 conducted by the Central Bureau of Statistics (CBS). The jobs table used data from the CBS National Travel Survey 1996. Land use data and historical development events came from the Israel Land Administration data for a 15-year period starting in 1985. Relocation rates were estimated annually based on the national Labor Force Survey conducted by the CBS, control totals were taken from the Israel National Outline Plan for 2020, digital land use layers were retrieved from the Hebrew University GIS database, and accessibility indices were derived from logsums generated by the Tel Aviv Metropolitan Area Travel Model.

The Tel Aviv UrbanSim (version 3) application was built following textbook instructions as much as possible (Felsenstein et al. 2007). The base year for the model was 1995 and we used 
a grid system of $250 \times 250 \mathrm{~m}$. This allowed us to include data available in the smallest census tracts of roughly $500 \times 500 \mathrm{~m}$ (the basic spatial data unit) without losing any information. Each grid cell and the data it contained was GIS-joined to its corresponding census tract. In multicell tracts, data were divided proportionately across cells. The most extensive metro area data sources were the 1995 national census and the 1996 national travel survey. Large amounts of data from these sources were imported directly into the model's databases. We modified the estimation procedure for the location choice models and for the estimation of land values and improvement values to meet the data available. Initially, land and improvement values were based on sample of 1000 residential, industrial and commercial property transactions made available by the Israel Land Administration. We used an inverse distance interpolation function to generate values for the whole metro area. Over time, we acquired more data and substituted real for synthetic values. For the household and jobs location model, in the absence of sample data, we used Monte Carlo sampling to generate data for 5000 households and jobs on which to run the estimations.

\section{Simultaneous Estimation: Empirical Results}

This section compares standard UrbanSim practice of estimating individual models for land prices and developer behavior (old) with the simultaneous estimation (new) of these two models. The parameters from each type of estimation are incorporated into the UrbanSim system. Residential and non-residential building densities and land values for the years 2001,2010, and 2020 are simulated using both methods. The land price model regresses the natural log of land prices on accessibility measures, gridcell attributes, characteristics of the surrounding area, and developer behavior using OLS. The developer behavior variable represents the various possible land conversions (intensification of existing development, transitioning to some other land use, or no further development). In UrbanSim, these are defined by 25 development types that refer to different levels of intensity of development for residential, mixed-use, commercial, industrial, and governmental land uses. In our model, while over 30 different transitions were recorded in practice, we estimated 20 different forms of conversion.

The developer model is a probit regression run for each type of development transition. The probability of conversion is estimated as a function of land values, accessibility and proximity variables, market conditions such as vacancy rates, and gridcell characteristics. It should be noted that due to the many forms of land conversion, some models have very few $(<50)$ cases. In addition, some combinations of conversion could not be estimated due to technical issues such as independent variables predicting the outcome perfectly, lack of variation in the dependent variable, or singular variance matrices that prevented the program from calculating true t-statistics.

We present an illustrative empirical simultaneous estimation for two conversion modelsnamely, developer behavior of the "no change" variety (from residential development to no further development) and the more likely case of land conversion from vacant developable to low-density residential status. We discuss thes results and progress from there to aggregate $\mathrm{Ur}$ banSim simulations for residential and non-residential densities and land values for the three time periods. After that, we disaggregate the simulation and present results for some of the largest towns within the metropolitan region. Finally, we validate the results against indepen- 
dent data, comparing our simulated results for 2001-2003 with real observed data for those years.

We illustrate this method using an UrbanSim (version 3) model calibrated for the Tel Aviv metropolitan area. We look at both non residential and residential densities and land values for the period 2001-2020. Our results for non-residential development show that using a simultaneous approach, non-residential development starts later but reaches more extreme values and makes for accentuated suburban non-residential development, more extreme values in non- residential land prices and a less smooth price gradient

For residential development we find that simultaneous estimation predicts more population deconcentration, residential land values are estimated to be higher in suburban locations than in the CBD. Individual estimation gives the opposite picture: higher residential prices closer to the CBD. Our conclusions discuss the meaning of the observed increased volatility in results induced by simultaneous estimation.

\subsection{Simultaneous Estimation}

We present two illustrative examples of the P2SLS results for land conversion. Table 1 shows the results for the probability of residential land not undergoing any further development. Table 2 shows the estimated results for the more probable case of vacant developable land being converted into low density residential development.

In the first case (Table 1), land prices are positively related to the relative density of both residential and commercial development (number of units) implying some scale effects, distance from a highway and the existence of mixed use development. Land prices are also positively influenced by developer behavior. They are inversely related to distance from the CBD and percentage of water coverage in the area. Finally, the number of other nearby residential units and the development of large scale residential projects would seem to depress land prices. The developer decision to discontinue further residential development is positively related to the amount of similar and mixed-use development in close proximity. This behavior is also inversely related to the size of any future development and to proximity to a major highway, and is negatively affected by recent transitions of the same type of development nearby. Land prices show a negative but insignificant effect on this behavior. All told, these results are generally as expected. We might have expected that land prices positively reinforce developer behavior (developers build where prices are expected to be high) but our model cannot confirm this. Our model does, however, show that land prices are themselves positively influenced by developer expectations returns to their actions. In addition the fact that prices drop off with distance from the $\mathrm{CBD}$ and increase with respect to relative density of development is in line with standard urban economics models (e.g. Fujita 1989; Mills 1972).

In the second case (Table 2), land prices are (as expected) driven by developer behavior and by the existing number of residential low-density units. This plausibly implies that low-density residential development attracts more of the same. Land prices are also inversely related to distance from the CBD (as expected) and to the density of residential units (of all kinds) in the immediate vicinity. Thus, dense residential development would seem to depress low-density residential prices. Overall, this land price model based on only a few significant explanatory variables has limited explanatory power. The probit estimation for vacant land being converted into low-density residential development suggests that while land prices have the right sign, 
Table 1: Simultaneous estimation of land prices and developer behavior (land conversion from residential to no further development.

\begin{tabular}{|c|c|c|c|}
\hline \multicolumn{2}{|c|}{ ln Land Prices } & \multicolumn{2}{|c|}{$\begin{array}{l}\text { Developer Behavior } 2-(-1) \text { : Residential - } \\
\text { No Further Development }\end{array}$} \\
\hline Constant & $12.43^{* *}$ & Constant & $4.113^{*}$ \\
\hline Developer behavior & $0.541^{*}$ & In land prices & -0.1300 \\
\hline Travel time CBD & $-0.00253^{* *}$ & Access to arterial hwy. & $-0.5499^{*}$ \\
\hline Percent water & $-0.00710^{* *}$ & $\begin{array}{l}\text { Recent transitions to resid. } \\
\text { (walking dist.) }\end{array}$ & -0.58853 \\
\hline In resid. units walking dist. & $-0.0808^{* *}$ & $\begin{array}{l}\text { Recent transitions to same } \\
\text { type (walking dist.) }\end{array}$ & $-1.4915^{* *}$ \\
\hline In distance highway & $0.0468^{* *}$ & $\begin{array}{l}\text { Percent mixed use (walking } \\
\text { dist.) }\end{array}$ & $0.5465^{*}$ \\
\hline $\ln$ commercial $\mathrm{m}^{2}$ & $0.0199^{* *}$ & $\begin{array}{l}\text { Percent same type cells } \\
\text { (walking dist.) }\end{array}$ & $0.01518^{*}$ \\
\hline Residential large-scale & $-2.377^{* *}$ & ln resid. units & $-0.8216^{* *}$ \\
\hline$-2_{\log }$ likelihood & - & & -57.634 \\
\hline$N$ & 2919 & & 238 \\
\hline$R^{2}$ & 0.73 & & - \\
\hline $\operatorname{LR} \chi^{2}$ & - & & 214.5 \\
\hline
\end{tabular}

their effect is not significant. The scale effect shows up as positive, indicating mimicking behavior. However, the model also gives mixed signals with respect to the effect of changes in the immediate vicinity on developer's decisions. On the one hand, past behavior (recent transitions to residential development) seems to be a key to the present and exerts a positive effect. On the other hand, recent transitions at the gridcell level seem to have the opposite effect.

\subsection{Residential and Non-Residential Metropolitan Land Use Change 2001-2020}

We now compare simulated land use change for the years 2001, 2010, and 2020 (base year 1995) using individual estimation (old) and simultaneous estimation (new). We do this for both residential and non-residential land use. Rather than present the aggregate picture for the whole metropolitan area, we have chosen to present the results across a northwest-southeast transect of the area that takes in the inner city (Tel Aviv), intermediate ring (Petach Tikva and Rishon Leziyon), and suburban (Modiin) sections of the metropolitan area.

Turning first to residential density change (Figure 3), we can see that simultaneous estimation predicts more population deconcentration than individual estimation. Both methods predict that the trend of residential sprawl will intensify, but the trend is stronger under the simultaneous approach. The area between the intermediate ring (Rishon Leziyon) and the outer suburbs (Modiin) is predicted to fill in. In the case of residential land values, the simultaneous estimation gives higher values in suburban locations than in the CBD. Over time, suburban residential land values are predicted to increase. In contrast, individual estimation gives an op- 
Table 2: Simultaneous estimation of land prices and developer behavior (24-2): Vacant developable residential (low density).

\begin{tabular}{|c|c|c|c|}
\hline \multicolumn{2}{|c|}{ In Land Prices } & \multicolumn{2}{|c|}{$\begin{array}{l}\text { Developer Behavior (24-2): Vacant } \\
\text { developable - residential (low density) }\end{array}$} \\
\hline Constant & $11.56^{* *}$ & Constant & -2.766 \\
\hline Developer behavior & $0.665^{* *}$ & In land prices & 0.026 \\
\hline Travel time CBD & $-0.0066^{* *}$ & $\begin{array}{l}\text { Recent transitions to resid. } \\
\text { (walking dist.) }\end{array}$ & $0.625^{*}$ \\
\hline Percent water & $-0.0015^{* *}$ & $\begin{array}{l}\text { Recent transitions to same type } \\
\text { (walking dist.) }\end{array}$ & $-1.101^{* *}$ \\
\hline In resid. units walking dist. & $-0.0359^{*}$ & $\begin{array}{l}\text { Percent residential (walking } \\
\text { dist.) }\end{array}$ & 0.017 \\
\hline \multirow[t]{2}{*}{ ln resid. units } & $0.0337^{*}$ & $\begin{array}{l}\text { Percent same type cells } \\
\text { (walking dist.) }\end{array}$ & $0.018^{*}$ \\
\hline & & ln resid. units & $0.468^{* *}$ \\
\hline$-2_{\log }$ likelihood & - & & -40.177 \\
\hline$N$ & 2696 & & 315 \\
\hline$R^{2}$ & 0.25 & & - \\
\hline $\operatorname{LR} \chi^{2}$ & - & & $58.5^{* * *}$ \\
\hline
\end{tabular}

posite picture with values in the suburbs (Modiin) staying relatively lower than those in the $\mathrm{CBD}$ and in intermediate locations (Petach Tikva and Rishon Leziyon). This pattern also intensifies across the metropolitan area over the three time periods (Figure 4).

For non-residential land use, we first observe changes in the density of commercial areas (Figure 5). Both methods of estimation show increasing suburban density implying employment sprawl that accompanies residential sprawl. However the simultaneous estimation shows this development starting later and reaching more extreme values by 2020. Thus, while both methods describe similar trends, the simultaneous estimation method predicts stronger suburban non-residential development. For example, commercial density in suburban Modiin for 2020 is predicted to be two to five times higher using the simultaneous approach. Turning to non-residential land values (Figure 6), we can see that the simultaneous estimation predicts more extreme values in non- residential land prices and a less-smooth price gradient from the CBD. In contrast, the individual estimation method predicts a trend of increasing land price dispersion across the metropolitan area interspersed with the emergence of new sub-centers of non-residential activity.

In sum, a clear pattern seems to emerge when comparing the two methods. The simultaneous approach tends to predict more extreme outcomes and more volatile trends. The individual estimation approach tends to produce a smoothing effect on the outcomes, with more consistent patterns emerging over time. 


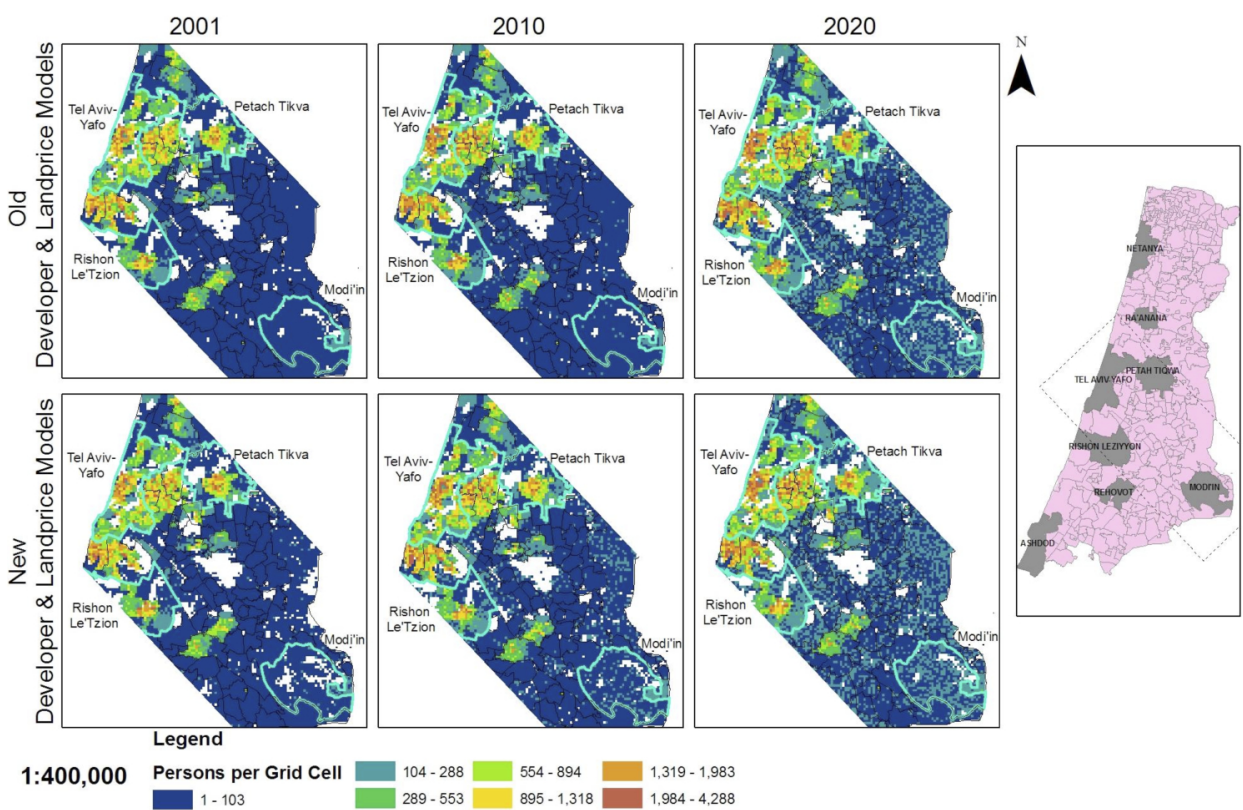

Figure 3: Residential density (persons per grid cell), 2001-2020.

\subsection{Disaggregated Results}

We now present results for the leading local authorities within the Tel Aviv metropolitan area, again comparing the predicted incremental change $(\Delta)$ attributable to the new method over the old one. This is done for the seven of the largest cities whose population sizes range from 75000 (Raanana) to nearly 400000 (Tel Aviv). These cities are also distributed across the whole metropolitan region avoiding any localized clustering effects (Figure 3). We present results relating to households and gridcells.

In relation to the former, we observe change in the number of households and average household income (Table 3). The simultaneous estimation method offers more volatile estimations of household income for some cities ranging from 10-20 percent more over the short term (2001). These results seem to stabilize over the longer term (2020), at which time the difference between the two estimation methods ranges from -1 to +3 percent. For the number-ofhouseholds variable, simultaneous estimation again generally yields higher outcomes (positive $\Delta$ 's) but these are of lower magnitude and more stable over time than estimates for household income.

When observing the changes in attributes of grid cells due to the two methods of estimation, we can note that the $\Delta$ values for non-residential cells (units, area) are much more volatile than the $\Delta$ values for residential cells. This supplements results that we found in the previous section (6.1) at the metropolitan level where non-residential land values were also more accentuated than residential values. In the present case, the values of the estimated change in commercial land use under the two methods, range from three percent to 65 percent across the different cities and this difference tends to increase over time for all cities rather than narrow (Table 4). 


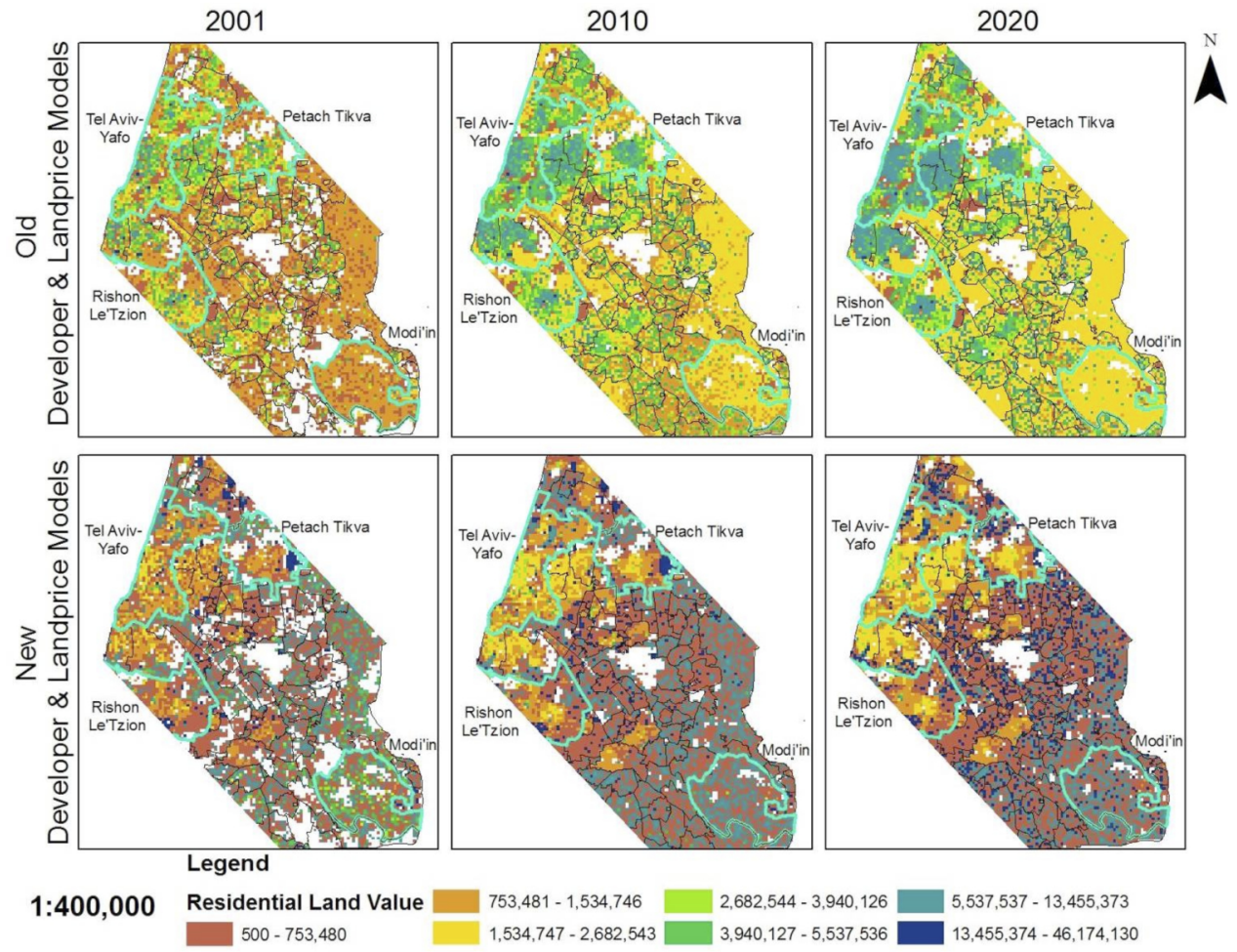

Figure 4: Residential land values, 2001-2020.

Table 3: Differences in household attributes due to two methods of estimation (percentage change).

\begin{tabular}{lcccccccc}
\hline & \multicolumn{3}{c}{ Avg. Household Income } & & \multicolumn{3}{c}{ Number of Households } \\
\cline { 2 - 4 } \cline { 7 - 8 } City & $\Delta 2001$ & $\Delta 2010$ & $\Delta 2020$ & & $\Delta 2001$ & $\Delta 2010$ & $\Delta 2020$ \\
\hline Ra'anana & 0 & 1 & 1 & & 1 & 5 & 5 \\
Petah Tikva & 12 & -2 & 1 & & 0 & 2 & 2 \\
Netanya & 2 & -4 & 2 & & 2 & 1 & 1 \\
Rehovot & 10 & 2 & -1 & & -1 & 2 & 2 \\
Rishon Leziyon & 20 & 2 & 0 & & 0 & 1 & 1 \\
Ashdod & 9 & 11 & 1 & & 1 & 2 & 2 \\
Tel Aviv & 5 & 1 & 3 & & 3 & 1 & 1 \\
\hline
\end{tabular}

The change in grid cells for residential land use is measured in two ways. We look at change in the number of residential units (Table 5) and change in the share of grid cells dedicated to residential land use (Table 6). In the former case, simultaneous estimation yields results similar to independent estimation with a tendency to estimate slightly less units (negative $\Delta$ ) in some of the cities in the short run. Over the long term, this under-estimation switches to a slight overestimation. In the case of estimating the share of residential land, simultaneous estimation yields consistently large and negative differences compared with independent estimation for 2001. By 2020 , the difference between the estimates has closed to a great extent. For the cities north of 

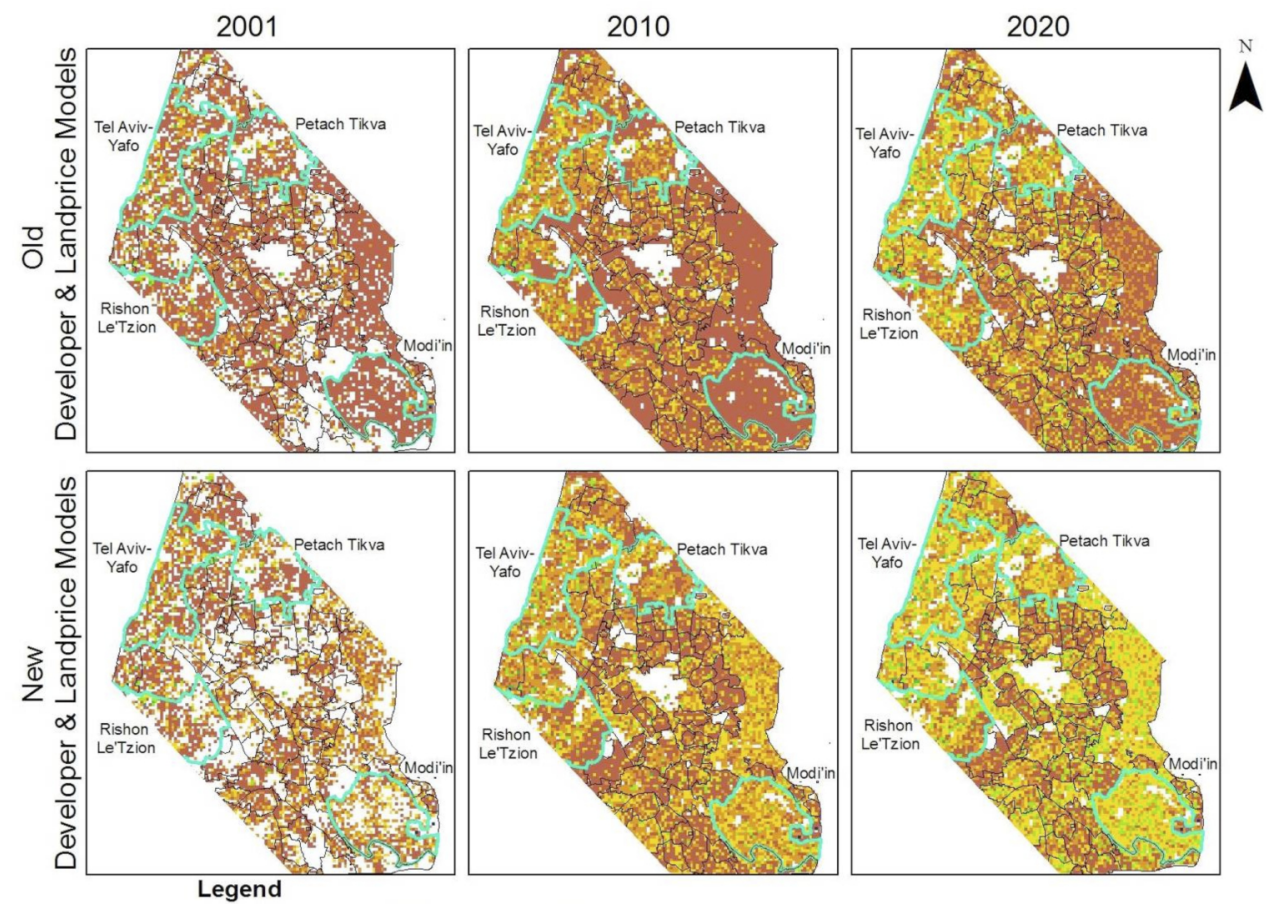

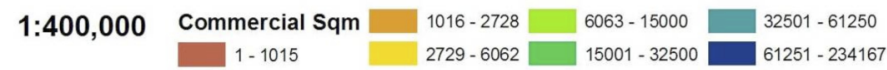

Figure 5: Density of commercial development $\left(\mathrm{m}^{2}\right), 2001-2020$.

Table 4: Differences in grid cell attributes: estimated commercial land use (percentage change).

\begin{tabular}{lccc}
\hline & \multicolumn{3}{c}{ Commercial Land Use $\left(\mathrm{m}^{2}\right)$} \\
\cline { 2 - 4 } City & $\Delta 2001$ & $\Delta 2010$ & $\Delta 2020$ \\
\hline Ra'anana & -18 & -4 & 0 \\
Petah Tikva & 27 & 39 & 43 \\
Netanya & 3 & 18 & 20 \\
Rehovot & 37 & 38 & 37 \\
Rishon Leziyon & 25 & 45 & 52 \\
Ashdod & 31 & 52 & 65 \\
Tel Aviv & 9 & 16 & 15 \\
\hline
\end{tabular}

Tel Aviv, $\Delta$ become slightly positive by 2020 . However, for the cities in the southern part of the metropolitan area (Rehovot, Rishon Leziyon, Ashdod) simultaneous estimation still yields negative $\Delta$ values. In general, simultaneous estimation predicts that cities south of Tel Aviv will gain much more in non-residential units than in residential units with all the implications for fiscal independence that this implies. 

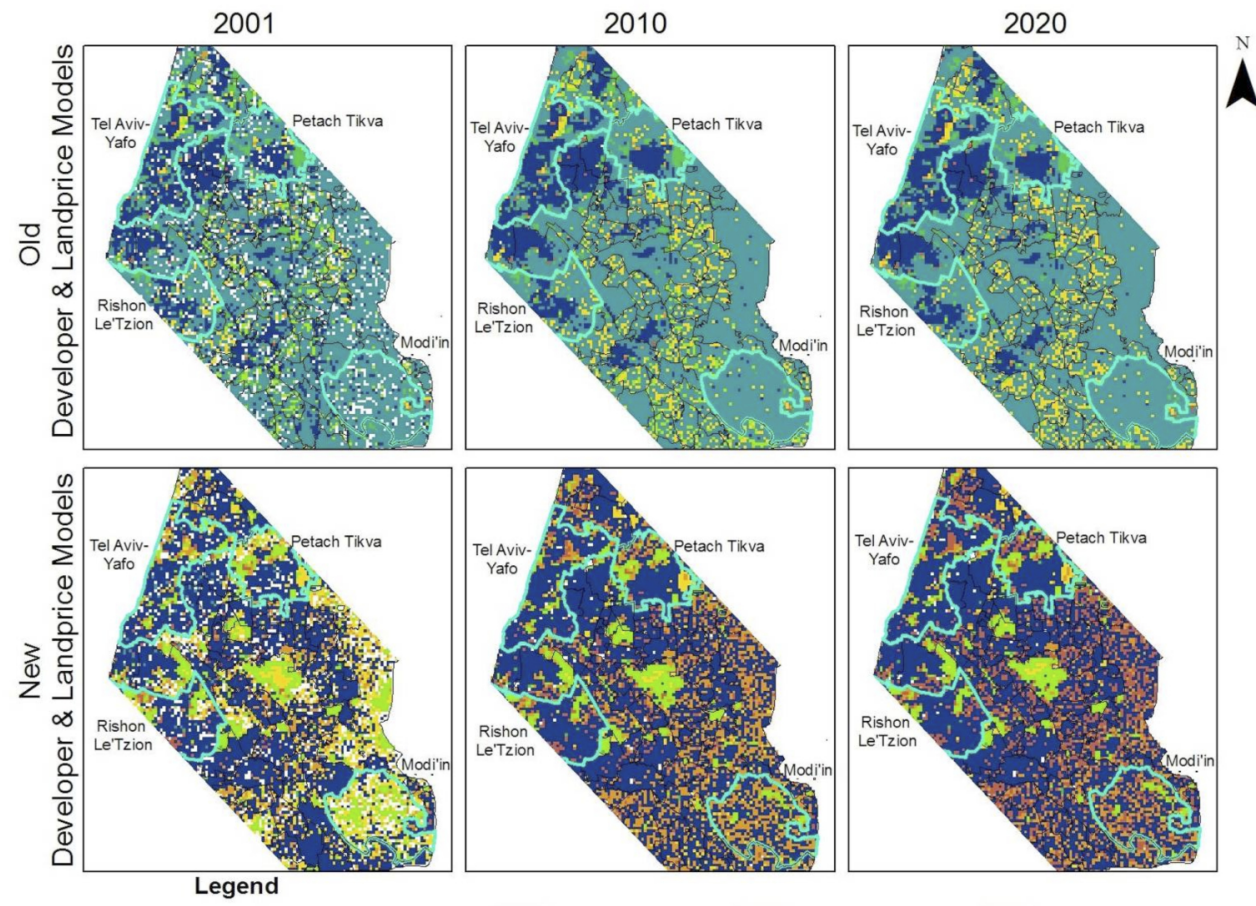

$1: 400,000$

Non Residential Land Value

$383,076-1,869,704$

$5,037,497-8,053,679$

$13,266,131-21,829,465$ 1 - 383,075

$1,869,705-5,037,496 \quad 8,053,680-13,266,130$
-

$21,829,466-39,620,356$

Figure 6: Non-residential land values, 2001-2020.

Table 5: Differences in grid cell attributes: number of estimated residential units (percentage change).

\begin{tabular}{lccc}
\hline & \multicolumn{3}{c}{ Residential Units } \\
\cline { 2 - 4 } City & $\Delta 2001$ & $\Delta 2010$ & $\Delta 2020$ \\
\hline Ra'anana & -2 & 2 & 4 \\
Petah Tikva & 0 & 1 & 3 \\
Netanya & 0 & 1 & 2 \\
Rehovot & -1 & 0 & 0 \\
Rishon Leziyon & -2 & 0 & 0 \\
Ashdod & 0 & 1 & 1 \\
Tel Aviv & 0 & 1 & 1 \\
\hline
\end{tabular}

\subsection{Validation of the Results}

The fact that simultaneous estimation produces estimates that are consistently larger or smaller than those produced by individual estimation is to be expected. Obviously, there will be more "noise" in the simultaneous estimation due to the use of fitted values (for example, for developer behavior in the land price model). In the absence of true BLUE estimation, goodness of fit in the simultaneous model is going to be less robust. However, the forecasts of the simultaneous 
Table 6: Differences in grid cell attributes: share of residential land use (percentage change).

\begin{tabular}{lccc}
\hline & \multicolumn{3}{c}{ Fraction Residential } \\
\cline { 2 - 4 } City & $\Delta 2001$ & $\Delta 2010$ & $\Delta 2020$ \\
\hline Ra'anana & -23 & 5 & 5 \\
Petah Tikva & -9 & 5 & 5 \\
Netanya & -6 & 2 & 2 \\
Rehovot & -17 & -2 & -2 \\
Rishon Leziyon & -19 & -1 & -2 \\
Ashdod & -8 & -3 & -4 \\
Tel Aviv & 0 & 1 & 1 \\
\hline
\end{tabular}

model are less likely to be biased. This results in forecasts that are consistently greater or smaller than those of the individual estimation.

A comparison of coefficients across the two estimation methods highlights this difference. For example, comparing the coefficients for the land price model in Table 1 with those estimated under individual estimation reveals that nearly all the coefficients are greater in the former (Table 7). As noted earlier (section 6.2) simultaneous estimation results in higher values overall, and also in higher values in suburban locations than in the CBD. While distance from the CBD is inversely related to land prices in both forms of estimation, its coefficient value is much larger in the case of individual estimation. This contributes to our finding that land prices under individual estimation show a different pattern with higher residential values closer to the $\mathrm{CBD}$ (Figure 4) and lower values in the suburban areas.

Table 7: Comparison of estimated coefficients for land price model (land conversion from residential to no further development).

\begin{tabular}{lcrr}
\hline & \multicolumn{3}{c}{ Estimation Method } \\
\cline { 2 - 4 } City & Simultaneous & Individual & \multicolumn{1}{c}{$\Delta$} \\
\hline Constant & 12.433 & 10.933 & 1.500 \\
Travel time CBD & -0.002 & -0.026 & -0.024 \\
ln resid. units & 0.104 & 0.026 & 0.078 \\
ln commercial m & 0.019 & 0.007 & 0.012 \\
Mixed use & 1.477 & 0.170 & 1.307 \\
\hline
\end{tabular}

Just how well do our simulated results, estimated either individually or simultaneously, match reality? As a test, we compare observed real data for 2002-2003 with our simulated results. This is done for four key variables for which CBS data exist at the city level: population, number of residential units, employment, and commercial floor space. Actual data is compared with simulated data for a series of medium-sized cities in the metropolitan area. For three of the four variables (population, employment and residential units) the estimates are close to the actual data. Figure 7 shows the ratio of actual to estimated population for five cities, 2002 and 2003. While both estimates are within the 80-100 percent range of the actual data, the simultaneous estimates are consistently larger than their individual counterparts. In the case of 
residential units, both types of simulation tend to overshoot the actual figures by 10-30 percent for the selected cities. In 2002, the simultaneous estimates are consistently higher than the individual estimates whereas in 2003 they are roughly equal (Fig 8). Employment figures are notoriously difficult to simulate. The UrbanSim estimates provide estimates that are in the range of 80-100 percent of the actual data for both methods with no over-shooting (Figure 9). The simultaneous method is consistently closer to reality than the individual method which yields more conservative estimates. Finally, the estimates for commercial floor space are generally weak. For four cities, the predicted figures are within the 70-100 percent range of the actual but for the other four, they are around 50 percent. In general, the results for this variable are volatile with no clear pattern emerging (Fig 10).

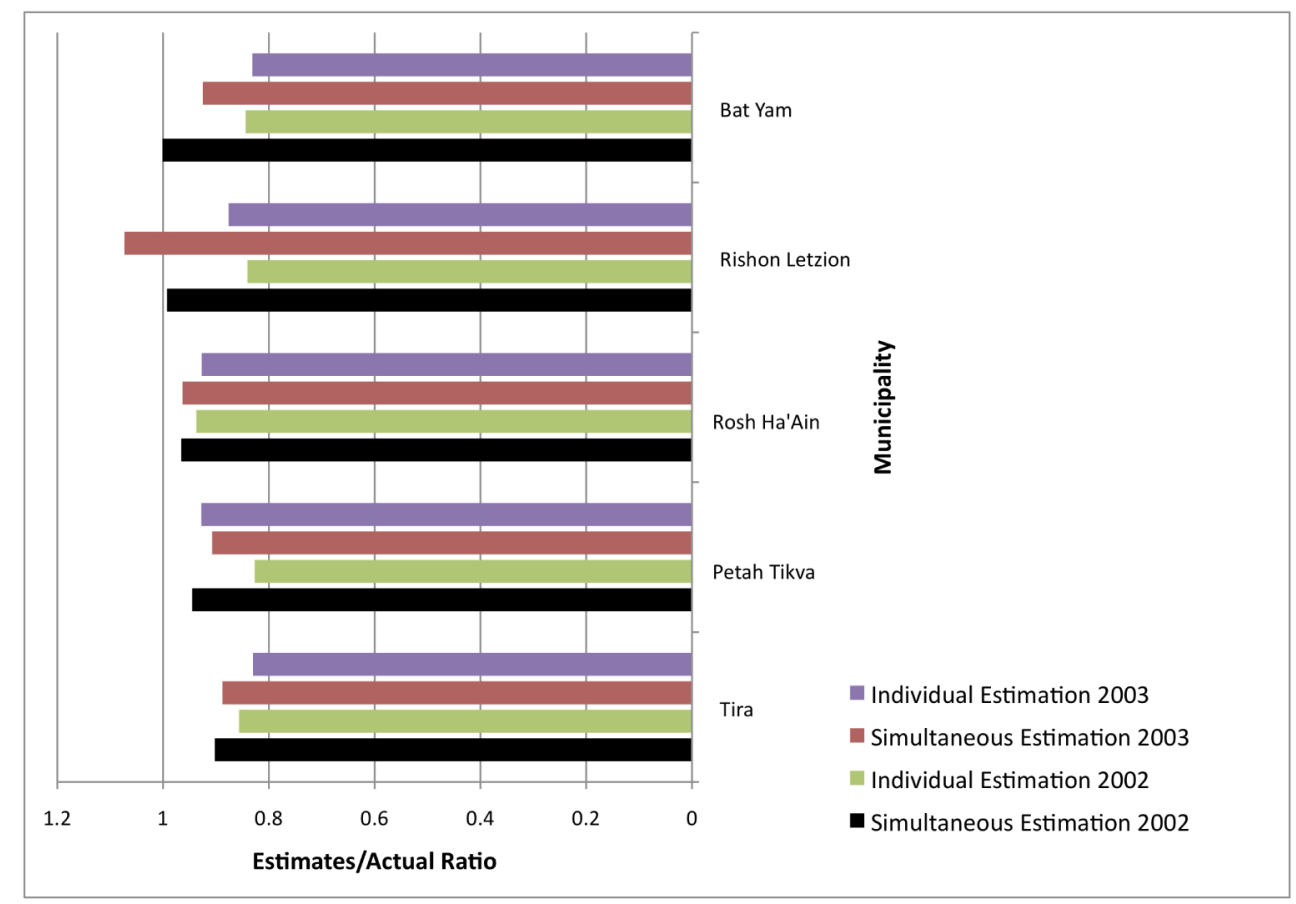

Figure 7: Actual versus estimated population, $2002 \& 2003$, select cities.

\section{Conclusions}

This paper has dealt with a focused issue relating to the UrbanSim approach to land use-transportation modeling. We have shown that behavior of two hitherto individual markets (developers and buyers) can be modeled as operating simultaneously. In addition, we have highlighted the difference that this behavioral interdependence makes to simulations over long and short terms. Inter alia, this has led to a discussion of the issues of endogeneity, identification, and dynamics in land use modeling. Strictly speaking, the behavioral approach advocated here features land users rather than land uses. The aggregate actions of land users results in land use change. This perspective does not focus attention on proactive agents of land use chang such as transportation systems. 


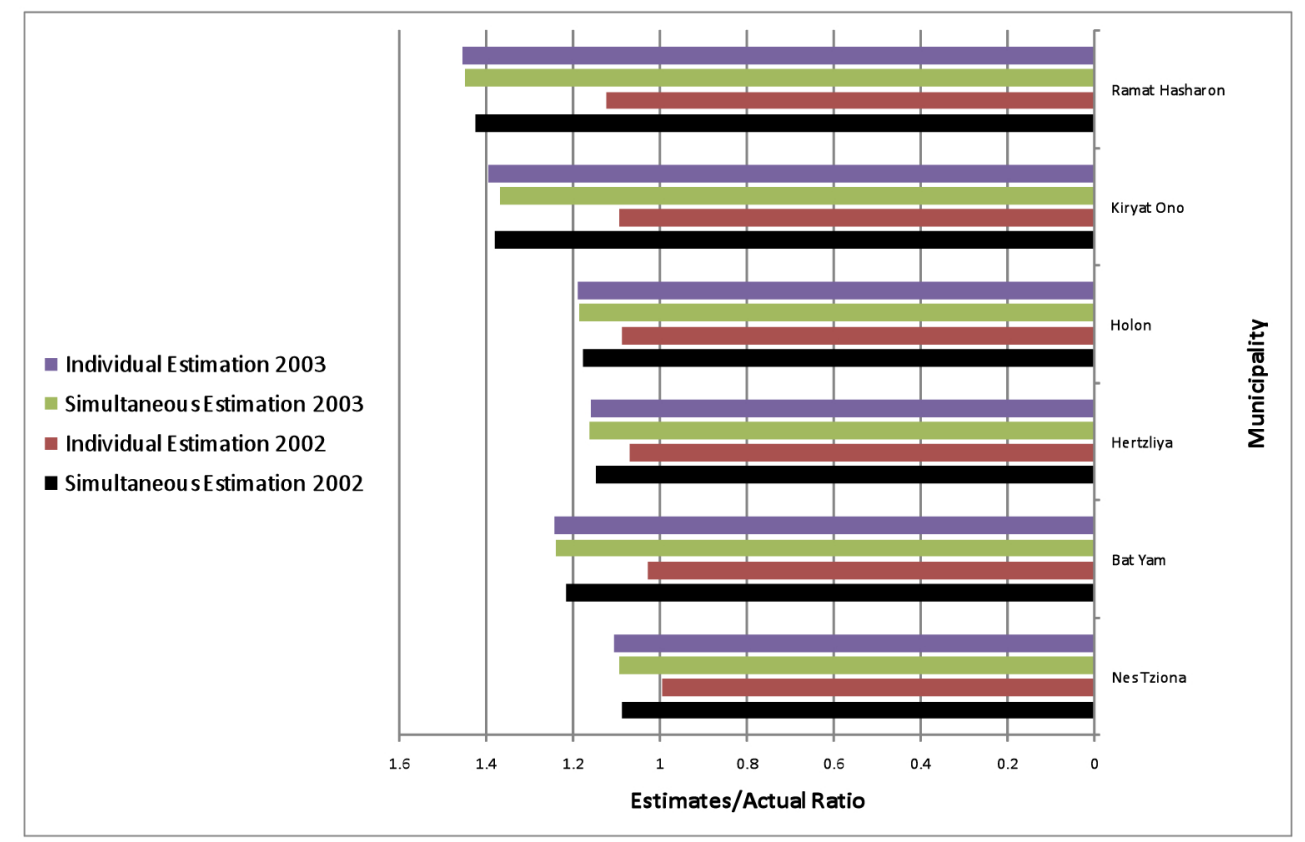

Figure 8: Actual versus estimated residential units, $2002 \&$ 2003, select cities.

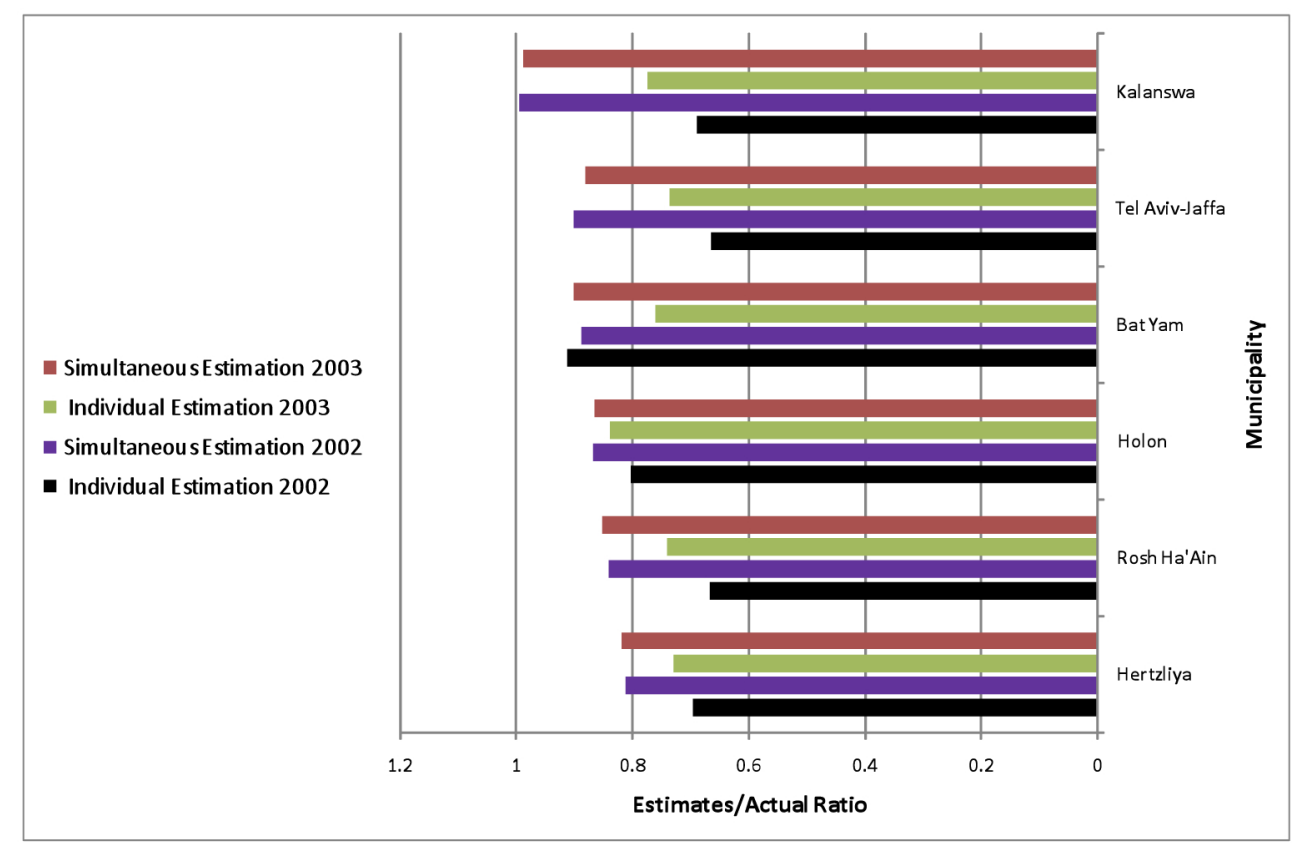

Figure 9: Actual versus estimated employment , $2002 \& 2003$, select cities.

In contrast to land uses, the behavior of land users is riddled with endogeneity. There are two main sources for this, one temporal and the other spatial. On the temporal side, previous behavior influences the present. Because time is unidirectional, one might think that only past behavior influences the present. However, future expectations must be considered as well. 


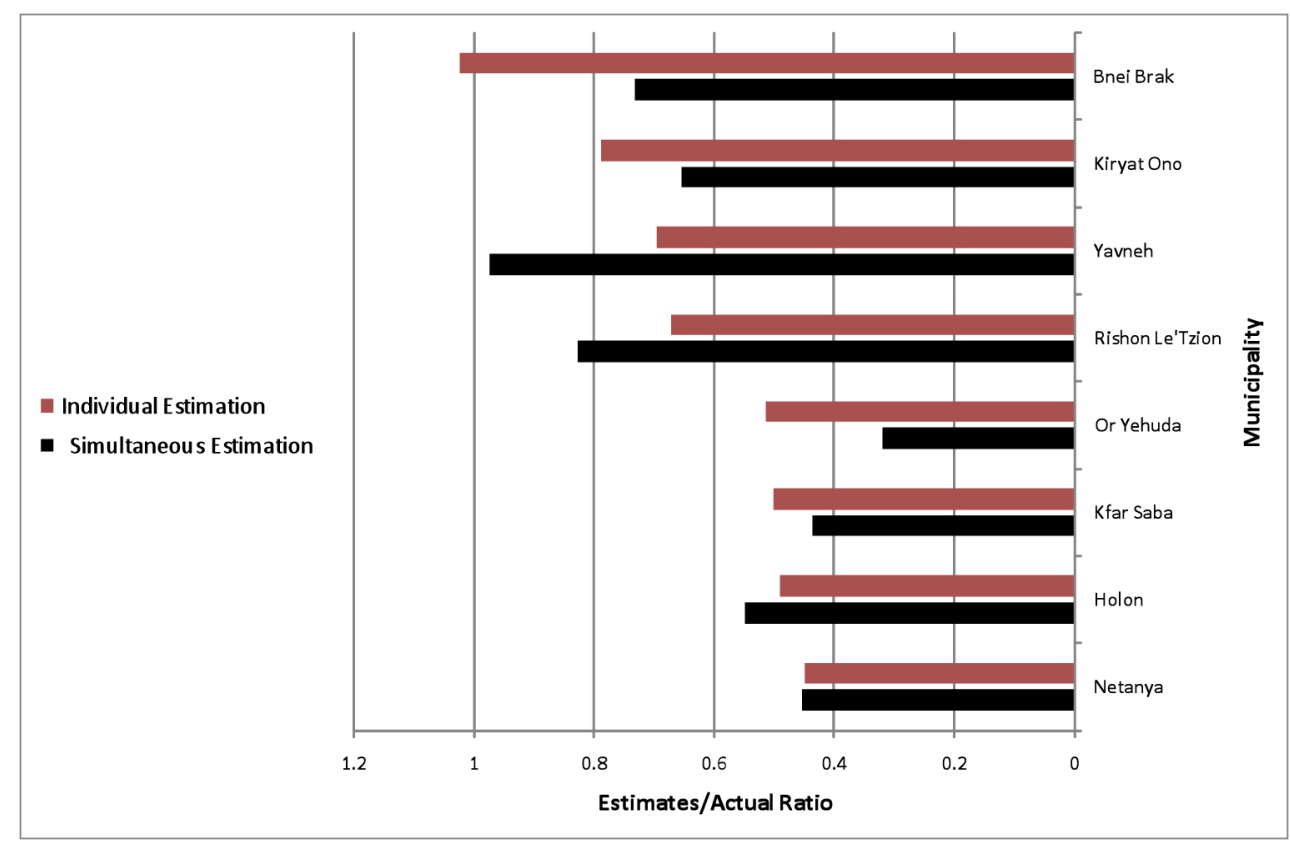

Figure 10: Actual versus estimated commmercial floor space, $2002 \& 2003$, select cities.

Both developers and buyers condition their behavior on expected utility or returns. Space also presents various challenges, commonly referred to as "spillovers." Behavior can be influenced by neighbors on all sides and from all directions. Thus, unraveling the effect of interdependence on the behavior of agents is a complicated matter. The issue is also acute when dealing with behavior that directly impacts land use. The interdependence between choosing a place of work and a place of residence is a well-known case in point.

In the current environment of land-use modeling, a variety of paths are being taken, including spatial interaction modeling, cellular automata, rule-based modeling, agent-based modeling, and microsimulation (Felsenstein et al. 2007; Koomen et al. 2007). For the more mechanistic of these approaches, inter-dependence is not an issue. However, for the more behavioral approaches in which developers, households, and workers are the agents of change, interdependence is obviously a key issue. A future challenge for injecting further realism into the submodels of UrbanSim would call for the incorporation of both spatial and temporal spillovers. In the case of the former, this means a more explicitly spatial econometric approach to model estimation in order to account for spatial dependencies in both the error and autoregressive components of the model. With respect to the temporal dimension, the challenge would seem to be coping with the non-stationarity inherent in much of the data driving UrbanSim. This means dealing with the unit roots and cointegrating processes behind the different data series underpinning the model. Incorporating these two together presents an exciting challenge for future research. 


\section{References}

Chang, J. S. 2006. Models of the relationship between transport and land-use: A review. Transport Reviews, 26(3):325-350. doi: 10.1080/01441640500468432.

de la Barra, T., B. Perez, and N. Vera. 1984. TRANUS-J: Putting large models into small computers. Environment and Planning B: Planning and Design, 11(1):87-101. doi: 10.1068/b110087.

de Palma, A. 2007. Discrete choice models with capacity constraints: An empirical analysis of the housing market of the greater Paris region. Journal of Urban Economics, 62(2):204-230. doi: 10.1016/j.jue.2007.02.007.

Ellickson, B. 1981. An alternative test of the hedonic theory of housing markets. Journal of Urban Economics, 9(1):56-79. doi: 10.1016/0094-1190(81)90048-6.

Felsenstein, D., E. Ashbel, and A. Ben-Nun. 2007. Microsimulation of metropolitan employment deconcentration. In E. Koomen, J. Stillwell, A. Bakema, and H. J. Scholten, eds., Modelling Land Use Change: Progress and Applications, volume 90 of GeoJournal Library, pp. 199-218. Netherlands: Springer. doi: 10.1007/1-4020-5648-6.

Fujita, M. 1989. Urban Economic Theory: Land use and city size. Cambridge and New York: Cambridge University Press.

Goffette-Nagot, F. 2008. Residential land prices and land demand in France: 1975-2001. GATE, CNRS-University of Lyon.

Hunt, J., J. E. Abraham, A. T. Brownlee, and M. Zhong. 2005a. Using input-output tables in spatial economic modelling. In International Conference on Computers in Urban Planning and Urban Management. University of Hong Kong.

Hunt, J., D. Kriger, and E. Miller. 2005b. Current operational urban land-use-transport modeling frameworks: A review. Transport Reviews, 25(3):329-376.

Hunt, J. and D. Simmons. 1993. Theory and application of an integrated land-use and transport modelling framework. Environment and Planning B: Planning and Design, 20(2):221-244. doi: 10.1068/b200221.

Iacono, M., D. Levinson, and A. El-Geneidy. 2008. Models of transportation and land use change: A guide to the territory. Journal of Planning Literature, 22(4):323-340. doi: $10.1177 / 0885412207314010$.

Ihlanfeldt, K. R. 2007. The effect of land use regulation on housing and land prices. Journal of Urban Economics, 61(3):420-435. doi: 10.1016/j.jue.2006.09.003.

Keshk, O. M. G. 2003. CDSIMEQ: A program to implement two-stage probit least squares. The Stata Journal, 3(2):157-167.

Kipnis, B., ed. 2009. Tel Aviv-Yafo: From a Garden Suburb to a World City. Haifa: Pardes Publications.

Koomen, E., J. Stillwell, A. Bakema, and H. J. Scholten. 2007. Modelling Land-Use Change: Theories and Methods. Springer.

Maddala, G. S. 1983. Limited Dependent and Qualitative Variables in Econometrics. Number 3 in Econometric Society Monographs. Cambridge, UK: Cambridge University Press.

Martinez, F. 1992. The bid - choice land-use model: an integrated economic framework. Environment and Planning A, 24(6):871-885. doi: 10.1068/a240871.

Martinez, F. 1996. MUSSA: Land use model for Santiago City. Transportation Research Record: Journal of the Transportation Research Board, 1552:126-134. doi: 10.3141/1552-18. 
Martinez, F. 2000. Towards a land use and transport interaction framework. In D. A. Hensher and K. Button, eds., Handbook of Transport Modeling, Handbooks in Transport, chapter 9, pp. 154-164. Elsevier.

Mayer, C. J. and C. T. Somerville. 2000. Land use regulation and new construction. Regional Science and Urban Economics, 30(6):639-662. doi: 10.1016/S0166-0462(00)00055-7.

Mills, E. S. 1972. Studies in the Structure of the Urban Economy. Baltimore, Maryland: The Johns Hopkins Press.

Putnam, S. 1996. Extending DRAM model: Theory-practice nexus. Transportation Research Record, 1552:112-119. doi: 10.3141/1552-16.

Rosen, S. 1974. Hedonic prices and implicit markets: Product differentiation in pure competition. Journal of Political Economy, 82(1):34-56.

Waddell, P. 2005. Confronting the bane of endogeneity in modelling urban social dynamics. In Proceedings of the Workshop on Modelling Urban Social Dynamics. University of Surrey, UK.

Waddell, P., A. Borning, M. Noth, N. Freier, M. Becke, and G. Ulfarsson. 2003. Microsimulation of urban development and location choices: Design and implementation of UrbanSim. Networks and Spatial Economics, 3(1):43-67. doi: 10.1023/A:1022049000877.

Waddell, P. and G. Ulfarsson. 2003. Dynamic simulation of real estate development and land prices within an integrated land use and transportation model system. In Proceedings of the 2003 TRB Annual Meeting. Transportation Research Board, Transportation Research Board. 